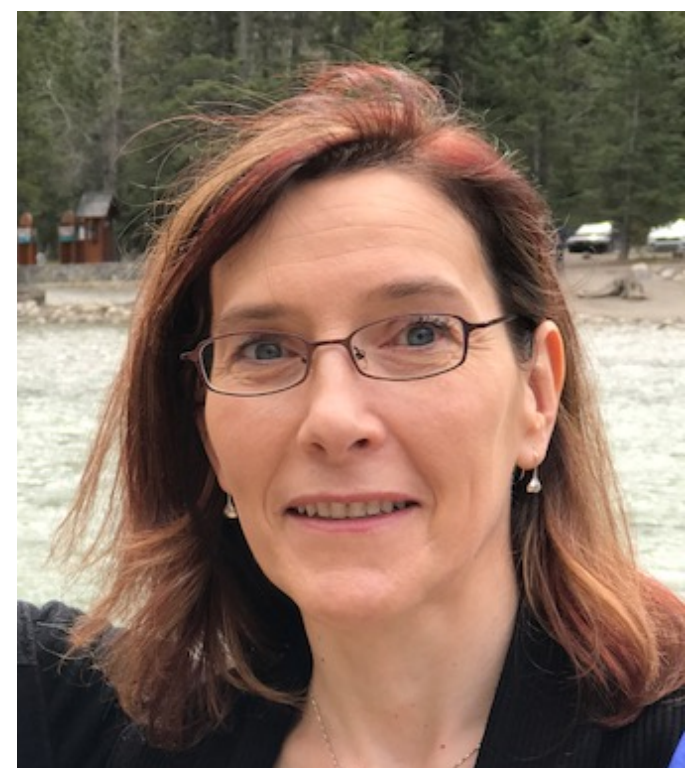

\title{
Western Faculty Profile: Dr. Carole Creuzenet
}

\author{
Kathleen $\mathrm{Qu}^{1}$ \\ ${ }^{1}$ Faculty of Schulich, Western University, London, Canada \\ No conflicts of interest declared
}

\section{Tell us about yourself and when you become interested in Microbiology.}

I am actually a biochemist by training and studied protein biochemistry during my doctorate at the French National Institute for Agronomical Research (INRA) in France. My postdoctorate at the Massachusetts Institute of Technology also involved protein biochemistry, in particular, I researched rhodopsin and eukaryotic signal transduction of light in the eye. While my work seemed to be quite far from the field of microbiology, my knowledge in enzymology eventually led me to opportunities that introduced me to microbiology.

Next up came my position as a Research Scientist at INRA. I was placed in the sector that focussed on food proteins and decided to work on taste perception because I suspected that it would involve proteins biochemically similar to rhodopsin. This was originally going to be my career but in 1998, my personal life called me to Guelph, Canada for a year and I had to look for a job. The Microbiology Lab run by Dr. Joseph Lam hired me as an enzymologist to determine the biochemical processes of the proteins involved in the synthesis of the lipopolysaccharides of Pseudomonas aeruginosa, a bacterium that endangers the lives of cystic fibrosis patients. Because I received a scholarship from the Cystic Fibrosis Foundation and thoroughly enjoyed my project, one year in Canada turned into three. During this time, I attended several conferences and met Dr. Miguel Valvano from the Microbiology and Immunology department at the University of Western Ontario (UWO) at a conference in Colorado. We determined that I had all the credentials to become a Professor at UWO and he offered me to apply for a position. After going through the application, interview, and receiving a salary award from NSERC, I became an official Microbiologist in 2001. I faced my first challenge right away: studying from Microbiology textbooks and research papers to be able to teach a fourth year Bacterial Pathogenesis course to the best of my abilities.

As you can see, the career I have now was not planned, it arose from taking various opportunities and exploring my interests. In fact, back in Dr. Lam's lab, I could have chosen to be separate from the microbiology aspect of my work but after seeing the effects of knocking out genes in the bacteria and making some knockout mutants of my own, I discovered that I loved this discipline. This made me consider being a hybrid biochemist and microbiologist and is what I am now in my lab. What I enjoy about working with bacteria is that there is always more to discover; you can never get bored!

\section{What was one of the most memorable moments in your research career?}

That would be my first publication during my doctorate in France. I put a lot of work into it, even having to volunteer months past my degree to finish the paper, and looking back, the topic was not one that I would have chosen myself. Nevertheless, I had this immense feeling of accomplishment! My goal still is to produce papers of great quality so every time I press that "submit" button, I get this little thrill that brings me back to that first paper. Another memorable moment would be presenting at my first conference. It was exhilarating to be surrounded by people who were so interested in my work, especially when contrasted to feeling a bit isolated while working in the lab.

\section{What advice would you give to an undergraduate student interested in doing research in Microbiology?}

Don't shy away from anything - even if you don't think you know it all, you can learn on the spot. Microbiology is very interdisciplinary nowadays; it encompasses a wide range of knowledge and you'll be using many techniques so, like me, you won't come into it knowing everything and will have to be open to continuous learning. One of my first students wanted to be so sure that her experiment would work that she never felt ready to go to the bench. I encouraged her to start - if her bacteria die, we'll just grow them again; trial and error is fine! You'll face disappointments but once things start working, it'll be that much more satisfying. 
You must accept these failures, but remember to keep your integrity and report them because analyzing the cause of a failure will lead to a solution and success. I find that these failures and successes come in waves for a person at any level in research, but you are being trained and are learning throughout this entire process so there is no wasted effort, just be tenacious!

\section{What makes a research assistant candidate stand out from others?}

I look for someone who is interested in my research. It's very clear when someone is applying solely for the purpose of getting a job and did not do any research on my work; I don't reply to these emails. Usually, there are papers and information on the researcher's website that the applicant can read and use to convey genuine interest in a cover letter or email. Then, when they come for the interview, they should have specific questions prepared to show that they are ready for the position. It is also important that the personalities of the student and the professor fit. I have found that there is little correlation between grades and ability to do well in the lab. However, grades are an indicator of competency in scientific writing, so I set a lower boundary at $75 \%$. I also like to see activities in the curriculum vitae of applicants that show their dedication and leadership. I find hobbies such as "practicing piano for 10 years" and volunteer positions to be informative. I have also gone to past events held by the UWO Microbiology and Immunology Student Association and hired students who showed extra curiosity in the field.

\section{What is a topic that should be a priority in Microbiology research in your opinion?}

I would say antibiotic resistant bacteria. People are not accepting the fact that this is happening and that antibiotics are becoming obsolete but this has become a massive problem. The issue is now publicly recognized, with the World Health Organization recently publishing their list of high priority pathogens with antimicrobial resistance. We need to have different approaches to find alternatives to current antibiotics. The longstanding goal has been to kill the bacteria but undoubtedly the bacteria will try to resist to these compounds to preserve their lives. The new mentality, which I have been following in my lab, is to prevent the bacteria from causing disease. For example, if you prevent the bacteria from colonizing deep tissues, maybe they can be expelled by the body or reside in a more superficial

\section{To Learn more on Dr. Creuzenet's lab and research, please visit her website at:}

\author{
http://publish.uwo.ca/ ccreuzen/
}

